\title{
Invasive fungal infections in transplant recipients
}

\author{
Jose A. Vazquez, Marisa H. Miceli and George Alangaden
}

\begin{abstract}
Invasive fungal infections are an important cause of morbidity and mortality in hematopoietic stem cell transplant and solid organ transplant recipients. Evolving transplant modalities and techniques, complex and extensive immunosuppressant strategies, and the increased use of broad spectrum antifungal prophylaxis has greatly impacted the epidemiology and temporal pattern of invasive fungal infections in the transplant population. The goal of this article is to provide an up-to-date review of the most commonly encountered invasive fungal infections seen in transplant recipients, including epidemiology, risk factors, clinical features, diagnostic dilemmas, management and their overall influence on outcomes.
\end{abstract}

Keywords: transplant recipients, Candida, Aspergillus, Mucor, antifungal agents

\section{Introduction}

Recent advances and improvements in medical therapeutics, chemotherapy, and organ transplantation methodology have substantially reduced the overall morbidity and mortality associated with transplantation. However, along with these improvements, a variety of opportunistic infections frequently caused by relatively avirulent organisms have emerged. Critically ill, immunocompromised patients, especially those who have undergone transplants, are the prime targets for these opportunistic fungal infections, primarily due to Candida and Aspergillus spp. This increase is multifactorial in origin and reflects increased recognition as well as a growing population of patients at risk.

\section{Candidiasis}

Candida spp. are ubiquitous fungi and are the most common fungal pathogens that affect humans [Vazquez and Sobel, 2011; Pfaller and Diekema, 2007]. The growing problem of systemic candidiasis reflects the enormous increase in the pool of patients at risk and the increased opportunity that exists for Candida spp. to invade tissues normally resistant to invasion. Candida spp. are true opportunistic pathogens that exploit recent technological advances to gain access to the circulation and deep tissues. Candida spp. are the most common cause of fungal infection affecting immunocompromised patients and are currently the fourth most common pathogen recovered from blood cultures [Pfaller and Diekema, 2007].

\section{Epidemiology}

Candida spp. produce a wide spectrum of diseases, ranging from superficial mucocutaneous disease to invasive illnesses, such as hepatosplenic candidiasis and systemic candidiasis [Vazquez and Sobel, 2011; Pfaller and Diekema, 2007]. Management of invasive candidiasis remains severely hampered by delays in diagnosis and the lack of reliable diagnostic methods that allow detection of both fungemia and tissue invasion by Candida spp. [Pappas, 2006; Pappas et al. 2003].

Over 165 species of Candida exist in nature; only a few species, however, are recognized causes of disease in humans (Table 1) [Vazquez and Sobel, 2011; Pfaller and Diekema, 2007; Pappas et al. 2003]. C. albicans and C. glabrata account for approximately $70-80 \%$ of Candida spp. isolated from patients with candidemia and invasive candidiasis. C. glabrata has recently become important because of its increasing incidence worldwide, and it is intrinsically less susceptible to azoles and amphotericin B (AmB) [Pfaller and Diekema, 2007; Morgan, 2005; Colombo et al. 2006]. C. krusei is also important because of its intrinsic resistance to most azoles, including ketoconazole, fluconazole, and itraconazole. In addition, it is less susceptible to AmB. Another
Ther Adv Infect Dis (2013) 1(3) 85-105 DOI: $10.1177 /$ 2049936113491936 (C) The Author(s), 2013. Reprints and permissions: http://www.sagepub.co.uk/ journalsPermissions.nav
Correspondence to: Jose A. Vazquez, MD, FACP, FIDSA Division of Infectious Diseases, Department of Medicine, Henry Ford Hospital, 2799 West Grand Blvd, CFP-202, Detroit, MI 48202, USA. jvazque1ahfhs.org

Marisa H. Miceli, MD George Alangaden, MD, FACP, FIDSA

Division of Infectious Diseases, Department of Medicine, Henry Ford Hospital, Wayne State University School of Medicine, Detroit, MI, USA 
important Candida spp. is C. lusitaniae; although not as common as some Candida spp., it is of clinical significance because it is frequently resistant to AmB, although it remains susceptible to azoles and echinocandins. C. parapsilosis is the second to third most common Candida spp. recovered from blood cultures and has become an important species to consider in hospitalized patients with vascular catheters. Additionally, in vitro susceptibility studies have shown a reduced susceptibility to echinocandins compared with the other Candida spp. [Eiland et al. 2008]. C. tropicalis is also considered an important cause of candidemia in patients with cancer (leukemia) and in those who have undergone hematopoietic stem cell transplantation (HSCT).

Candida spp. contain their own set of well recognized virulence factors. Although not well characterized, several virulence factors may contribute to their ability to cause infection [Yang, 2003]. As with most fungal infections, host defects play a significant role in the development of candidal infections. Numerous host defects have been associated with candidal infections. Risk factors associated with candidemia and systemic candidiasis include granulocytopenia, HSCT, solid organ transplants (SOTs) (kidney and liver), total parenteral hyperalimentation, solid neoplasm, corticosteroids, broadspectrum antibiotics, prolonged intensive care unit stay, prolonged hospitalization, mechanical ventilation for over 3 days, pancreatitis, severe trauma, recent surgery (especially gastrointestinal tract), central venous catheters, and hemodialysis [Vazquez and Sobel, 2011; Pappas, 2006].

\section{Clinical manifestation}

Infections due to Candida spp. can manifest in a wide spectrum of clinical syndromes as described below (Table 2) [Vazquez and Sobel, 2011; Pappas, 2006]. The clinical presentation can vary depending on the type of infection, the organ involved and the degree of immunosuppression.

Systemic candidiasis may be divided into two different categories: candidemia without organ involvement and disseminated candidiasis (organ infection by Candida spp.). Deep organ infections due to Candida spp. are generally observed as part of the disseminated candidiasis syndromes, which may be associated with either single- or multiorgan involvement. The patient's history commonly reveals the following: several days of fever that is unresponsive to broad-spectrum antimicrobials (frequently the only marker of infection), prolonged intravenous catheterization, and several key risk factors. Physical examination is remarkable for the following: fever, macronodular skin lesions (approximately $10 \%$ ), candidal endophthalmitis (approximately $5 \%$ ), and occasionally septic shock. Disseminated candidiasis is frequently associated with multiple deep organ infections or may involve single organ infection (Table 2).

\section{Diagnosis}

Unfortunately, findings from laboratory studies are either negative or nonspecific [Vazquez and Sobel, 2011; Pappas, 2006]. Clinicians are required to act definitively and early based on a high index of suspicion. Patients who remain febrile despite broad-spectrum antibiotic therapy, with either neutropenia or other risk factors and persistent leukocytosis, should be suspected of

Table 1. Candida spp. Why should they be identified?

\begin{tabular}{|c|c|c|}
\hline Candida species & Distribution (\%) & Comments \\
\hline C. albicans & $50-60$ & \\
\hline C. glabrata & $15-25$ & Less susceptible to all antifungals \\
\hline C. parapsilosis & $10-20$ & $\begin{array}{l}\text { Frequently catheter-related, less sus- } \\
\text { ceptible to echinocandins }\end{array}$ \\
\hline C. tropicalis & $6-12$ & Generally susceptible to all antifungals \\
\hline C. krusei & $1-3$ & $\begin{array}{l}\text { Intrinsically resistant to fluconazole and } \\
\text { itraconazole; less susceptible to AmB }\end{array}$ \\
\hline C. guilliermondi & $<1$ & Resistant to AmB \\
\hline C. lusitaniae & $<1$ & Resistant to AmB \\
\hline C. dubliniensis & $<1$ & Primarily recovered in patients with HIV \\
\hline
\end{tabular}


having systemic candidiasis. Cultures of nonsterile sites, although not useful for establishing a diagnosis, frequently demonstrate a high degree of candidal colonization. However, these positive cultures may be useful for initiating antifungal therapy in patients who are febrile and are

Table 2. Manifestations of invasive candidiasis.

- Fever unresponsive to broad-spectrum antimicrobials, frequently the only marker of infection, especially if:

- prolonged intravenous catheterization

- a history of several major risk factors

- possibly associated with multiorgan infection

- Physical examination is remarkable for the following:

- macronodular skin lesions ( 10-20\%)

- candidal endophthalmitis ( 5\%)

- occasionally, septic shock (hypotension, tachycardia, tachypneal

- multiorgan dysfunction, depending on the site affected

Vazquez and Sobel [2011]. unresponsive to broad-spectrum antimicrobials. It is important to always consider positive results from these sites significant and definitive evidence of infection. To be effective, appropriate antifungal therapy should be provided early and empirically in such high-risk patients [Morrell et al. 2005].

Recently, a newer diagnostic assay detecting the presence of 1-3 $\beta$-D-glucan (BG) Fungitell Assay (Associates of Cape Cod Incorporated, East Falmouth, MA, USA). in serum has been used as a diagnostic aid [Alexander and Pfaller, 2006; Odabasi et al. 2004]. $\beta$-D-glucan is a major component of the fungal cell wall of a wide variety of fungi and can be detected by its ability to activate factor $\mathrm{G}$ of the horseshoe crab coagulation cascade. This assay has a sensitivity of $75-100 \%$ and a specificity of $88-100 \%$ (Table 3). However, it is a broad-spectrum assay that can also detect Aspergillus, Fusarium, Acremonium, and Saccharomyces spp. [Odabasi et al. 2004].

Table 3. Characteristic features of biomarkers currently used for the diagnosis of invasive fungal infections.

\begin{tabular}{|c|c|c|c|}
\hline \multirow[b]{2}{*}{ Test features } & \multicolumn{3}{|l|}{ Biomarkers } \\
\hline & $1,3 \beta$-D-glucan (BG) & \multicolumn{2}{|c|}{ Galactomannan (GM) } \\
\hline Method & Biological cascade based assay & \multicolumn{2}{|c|}{ Anti-GM monoclonal antibody } \\
\hline Results interpretation & $\begin{array}{l}\text { Negative }<60 \mathrm{pg} / \mathrm{ml} \\
\text { Intermediate } 60-79 \mathrm{pg} / \mathrm{ml} \\
\text { Positive }>80 \mathrm{pg} / \mathrm{ml}\end{array}$ & \multicolumn{2}{|c|}{ Positive $>0.5$ index } \\
\hline Clinical applications & Useful for early detection & \multicolumn{2}{|c|}{$\begin{array}{l}\text { Useful for the early detection } \\
\text { of invasive aspergillosis in adults }\end{array}$} \\
\hline FDA approval & Serum & \multicolumn{2}{|c|}{ Serum, BAL } \\
\hline $\begin{array}{l}\text { Clinical significance } \\
\text { in diagnosis of IFI }\end{array}$ & $\begin{array}{l}\text { Sensitivity: } 77 \%(67-84 \%) \\
\text { Specificity: 85\% (80-90\%) }\end{array}$ & $\begin{array}{l}\text { Serum: } \\
\text { sensitivity } 41 \% \\
\text { (59-83\%) } \\
\text { specificity } 93 \% \\
(92-94 \%)\end{array}$ & $\begin{array}{l}\text { BAL: } \\
\text { sensitivity } 85 \% \\
\text { (72-92\%) } \\
\text { specificity: } 88 \% \\
\text { (78-92\%) }\end{array}$ \\
\hline \multicolumn{4}{|l|}{ Major caveats } \\
\hline Cross reactivity & $\begin{array}{l}\text { Pneumocystis jiroveci, Coccidioides } \\
\text { immitis, Histoplasma encapsulatum, } \\
\text { Candida spp., Acremonium, Fusarium spp., } \\
\text { Trichosporon spp., Aspergillus spp. }\end{array}$ & \multicolumn{2}{|c|}{$\begin{array}{l}\text { Aspergillus spp., Fusarium spp., } \\
\text { Paecilomyces, Penicillium spp., } \\
\text { Alternaria spp., Histoplasma } \\
\text { encapsulatum, Blastomyces } \\
\text { dermatitidis, Cryptococcus neoformans }\end{array}$} \\
\hline False positives & $\begin{array}{l}\text { Semisynthetic } \beta \text { lactam antibiotics } \\
\text { Hemodialysis with cellulose membranes } \\
\text { Bacteremia } \\
\text { Transfusion given through cellulose membranes } \\
\text { Exposure to gauze } \\
\text { Intravenous imunoglobulins and albumin }\end{array}$ & $\begin{array}{l}\text { Semisynthetic } \beta \\
\text { Mucositis or } \mathrm{GI} \\
\text { Multiple myelon } \\
\text { Plasmalyte use } \\
\text { Cotton swabs }\end{array}$ & $\begin{array}{l}\text { antibiotics } \\
\text { HD }\end{array}$ \\
\hline False negatives & Concomitant use of antifungals & \multicolumn{2}{|c|}{ Concomitant use of antifungals } \\
\hline
\end{tabular}


The BG assay does not detect infections caused by Cryptococcus neoformans or Mucor spp.

\section{Management}

The treatment of Candida infections varies substantially and is based on the anatomic location of the infection, the patients' underlying disease and immune status, the patients' risk factors for infection, the specific species of Candida responsible for infection, and in some cases, the susceptibility of the strain to the different antifungal drugs [Vazquez and Sobel, 2011; Pappas et al. 2009]. In January 2009, the Infectious Disease Society of America and the Mycosis Study Group published updated practice guidelines for the treatment of candidemia and candidiasis [Pappas et al. 2009].

Antifungal agents. Three major classes of systemic antifungal agents are available for the treatment of invasive fungal infections (IFIs): polyenes, azoles, and echinocandins [Sucher et al. 2009; Moen et al. 2009; Miceli and Chandrasekar, 2012; Kauffman, 2006; Sable et al. 2008]. Systemic agents with anti-Candida activity include $\mathrm{AmB}$ deoxycholate (AmB-d), fluconazole, voriconazole, caspofungin, micafungin, anidulafungin, lipid formulations of $\mathrm{AmB}$ (LFAmB) and flucytosine (Table 4).

Polyenes include AmB-d and the LFAmB (AmB lipid complex, liposomal amphotericin $\mathrm{B}$, and amphotericin B colloidal dispersion formulations) [Moen et al. 2009]. AmB was considered the gold standard of antifungal treatment for over 50 years. Unfortunately, its use is limited due to significant adverse events such as infusion-related reactions and nephrotoxicity. Lipid formulations of $\mathrm{AmB}$ were developed to overcome the limitations associated with the use of AmB-d. In general, LFAmB are better tolerated due to their different molecular structures. In fact, patients can be treated with larger doses of $\mathrm{AmB}$ without experiencing the typical side effects of AmB-d [Miceli and Chandrasekar, 2012]. The antifungal spectrum of activity, common drug-drug interactions, and side effects are shown in Table 4 .

The activities of these antifungal agents against Candida are predictable and vary with species (Table 5). The drug of choice for candidemia or invasive candidiasis depends on the infecting species and the clinical setting. C. albicans is the most susceptible species. C. parapsilosis tends to have higher minimum inhibitory concentrations
(MICs) in vitro and is less susceptible to echinocandin agents [Pappas et al. 2009; Kauffman, 2006; Sable, 2008]. C. glabrata is less susceptible to all antifungals and approximately $10-15 \%$ are intrinsically resistant to fluconazole. C. kruse $i$ isolates have the highest fluconazole and flucytosine MICs of any of the species. In addition, it is also resistant to itraconazole and $\mathrm{AmB}$ [Pfaller and Diekema, 2007; Morgan, 2005; Colombo et al. 2006] (Table 5).

Until recently, the use of $\mathrm{AmB}$ and fluconazole was the standard therapy for all forms of candidiasis [Charlier et al. 2006]. The primary difference between the newer guidelines and the prior guidelines has to do with the upfront use of echinocandins in patients with candidemia and suspected candidiasis who have moderate to severe infections, patients with infections due to $C$. glabrata and $C$. krusei, and those who have a history of prior azole exposure [Pappas et al. 2009; Vazquez and Sobel, 2006; Chandrasekar and Sobel, 2006; Kuse et al. 2007; Reboli et al. 2007; Cornely et al. 2007; Sobel and Revankar, 2007].

In the non-neutropenic adult patient with candidemia or invasive candidiasis, most infections are due to the presence of an intravascular catheter in up to $70 \%$ of patients [Pappas et al. 2003, 2009]. Removal of all intravascular catheters appears to shorten the duration of candidemia and has been associated with reduced mortality [Pappas et al. 2009; Andes et al. 2012].

Candidemia requires treatment in all patient populations. In most situations, either fluconazole or an echinocandin are the drug of choice in the management of candidemia and disseminated candidiasis. The options listed should be considered depending on the history of a prior exposure to antifungals, the probability of fluconazole resistance, the presence of comorbid conditions, and the clinical status of the patient. Fluconazole (loading dose of $800 \mathrm{mg}$, then $400 \mathrm{mg}$ daily) or an echinocandin (caspofungin: loading dose of $70 \mathrm{mg}$, then $50 \mathrm{mg}$ daily; micafungin: $100 \mathrm{mg}$ daily; anidulafungin: loading dose of $200 \mathrm{mg}$, then $100 \mathrm{mg}$ daily) are recommended as initial therapy for most adult patients [Pappas et al. 2009]. However, an echinocandin is preferred in patients with moderate to severe illness, in patients who have a recent azole exposure, and in patients infected with a non-albicans Candida spp. [Pappas et al. 2009; Sobel and Revankar, 


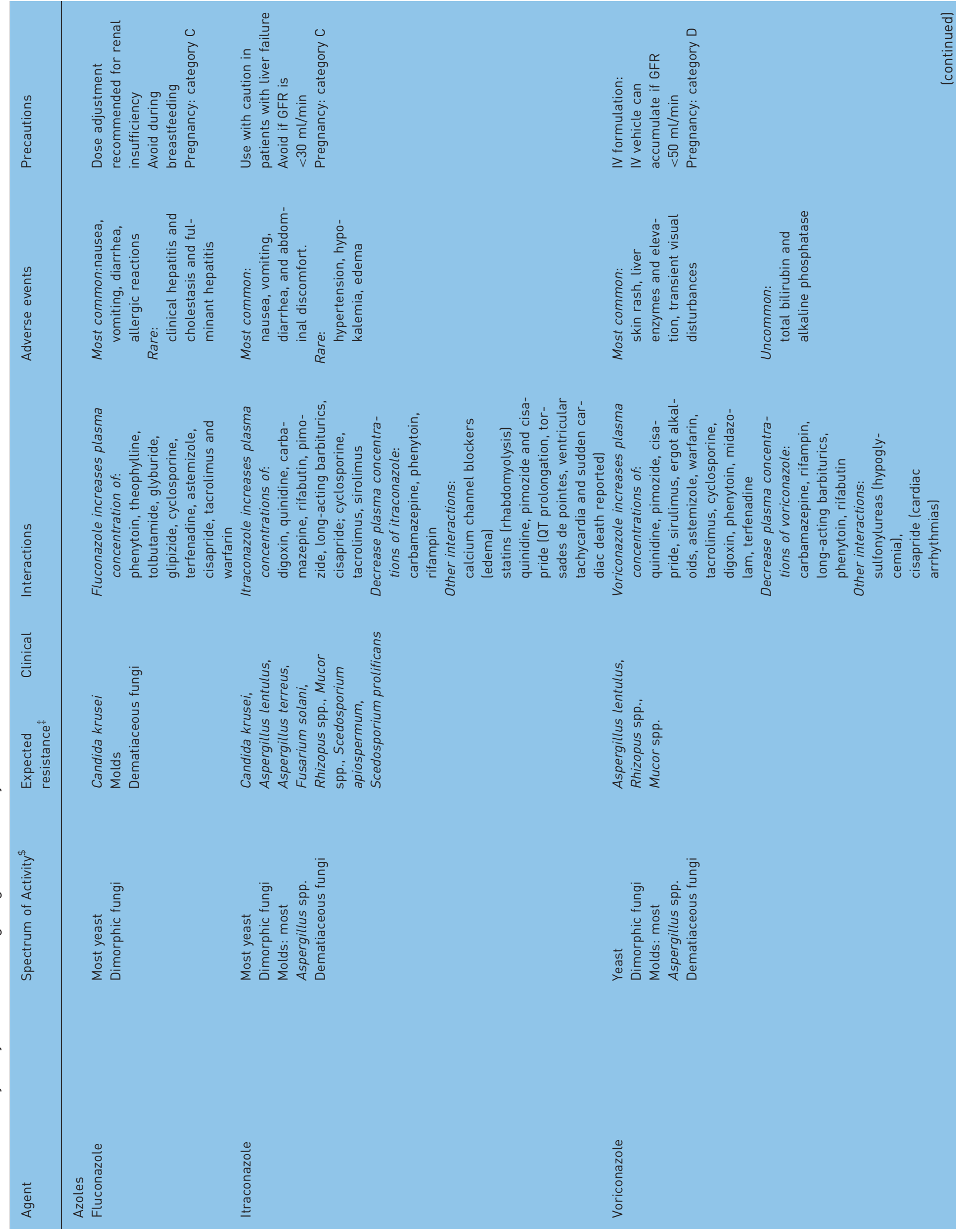




\begin{tabular}{|c|c|c|c|c|}
\hline 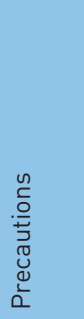 & 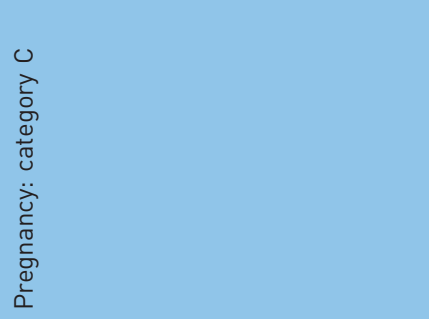 & 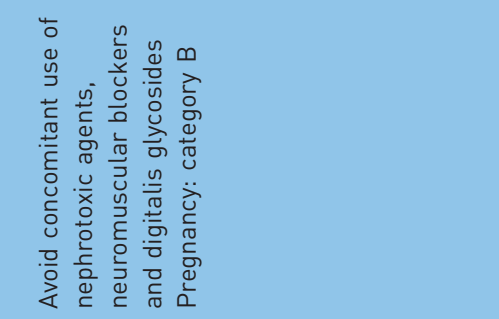 & & 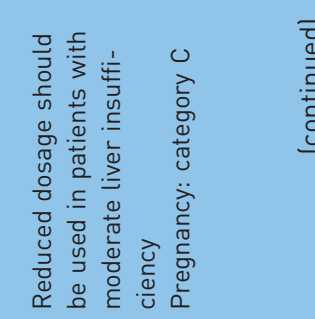 \\
\hline 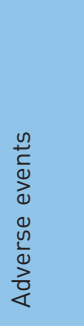 & 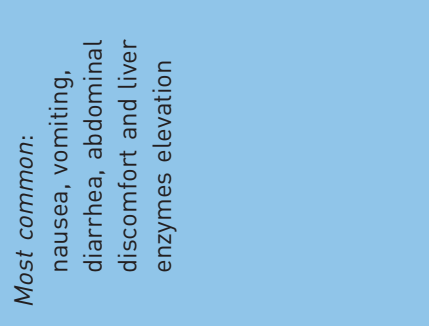 & 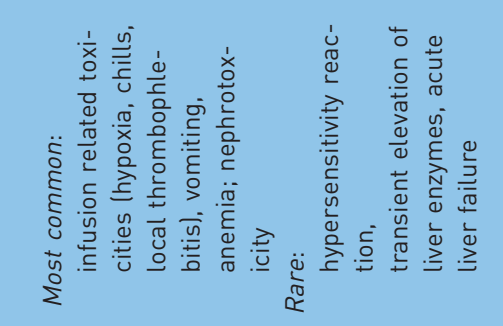 & 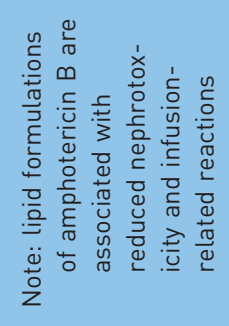 & 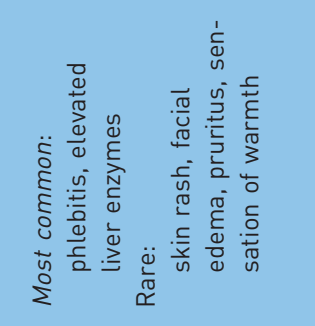 \\
\hline 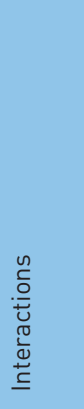 & 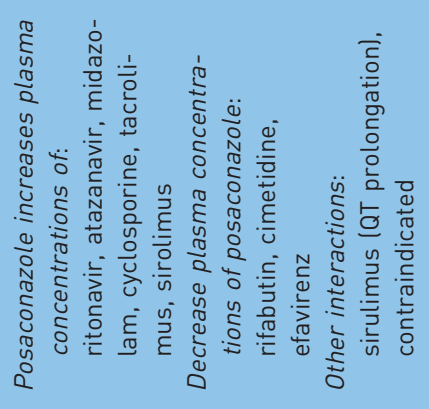 & 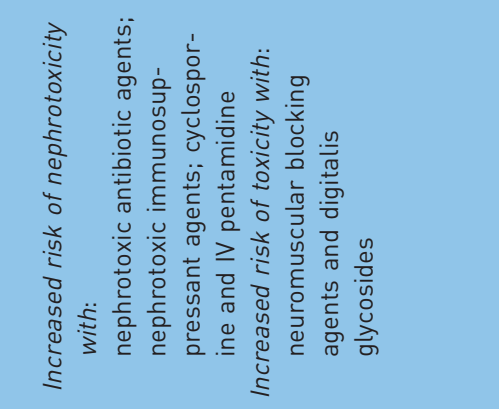 & & 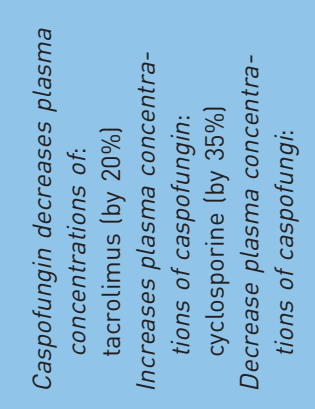 \\
\hline 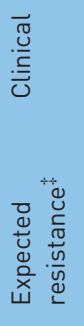 & 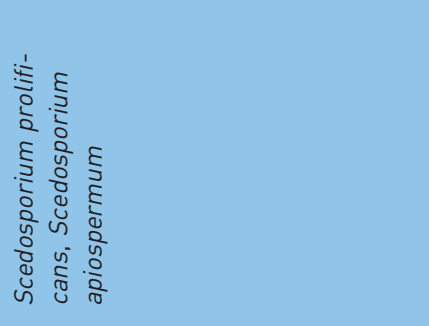 & 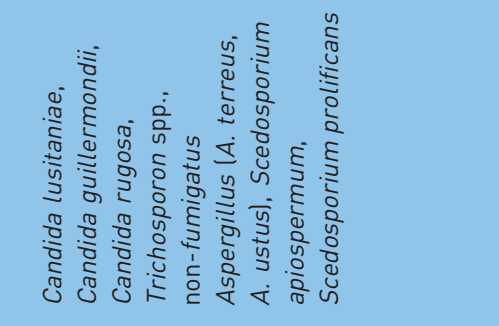 & & 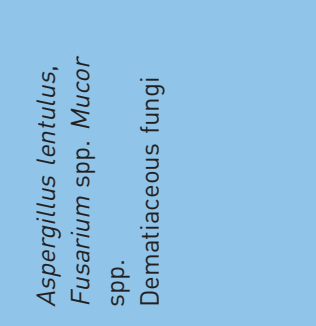 \\
\hline 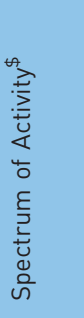 & 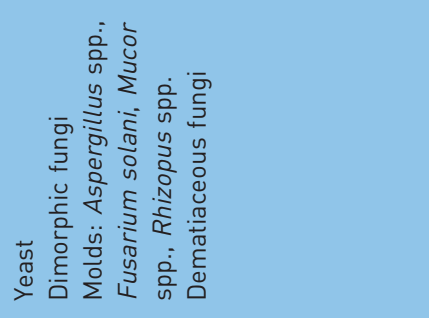 & 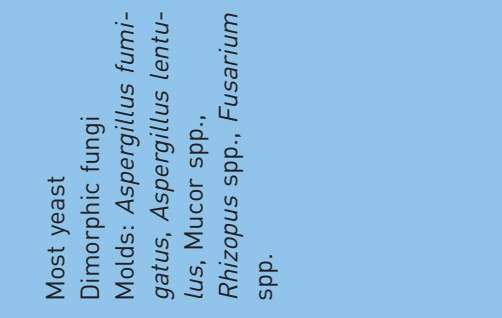 & & 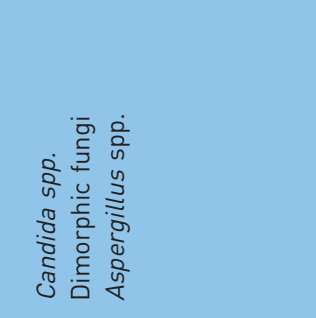 \\
\hline 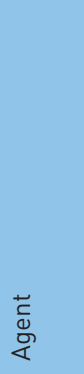 & 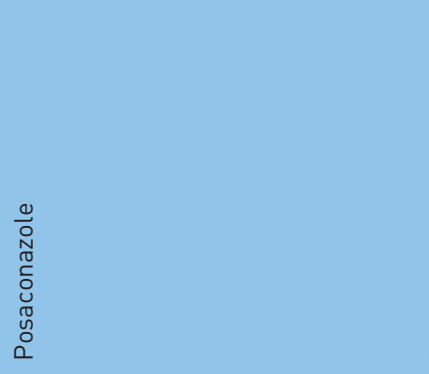 & 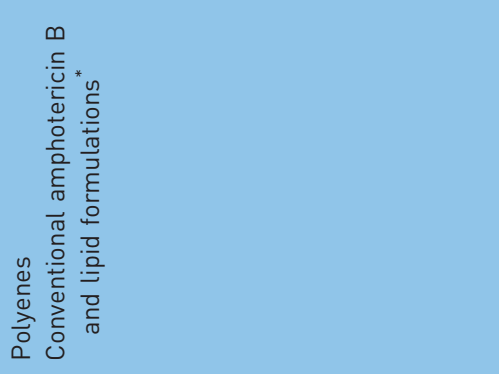 & & 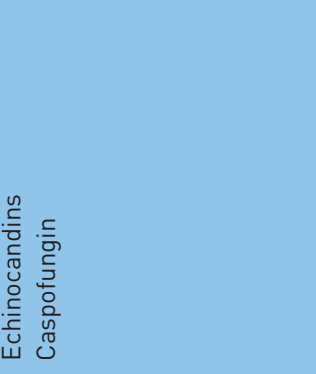 \\
\hline
\end{tabular}




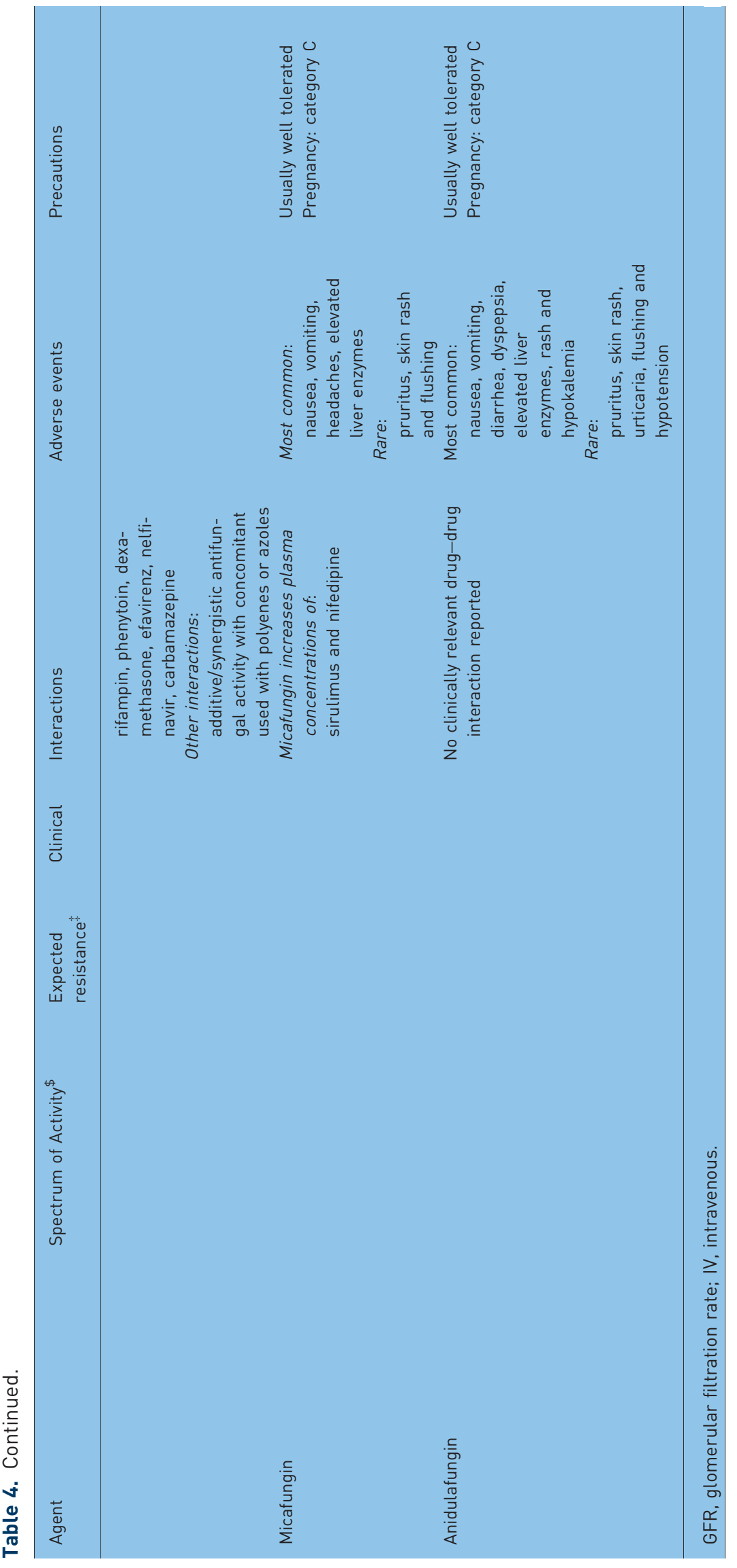


Table 5. General patterns of susceptibility of Candida species.

\begin{tabular}{llllll}
\hline Candida species & Fluconazole & Itraconazole & Voriconazole & Amphotericin B & Echinocandins \\
\hline C. albicans & S & S & S & S & S \\
C. tropicalis & S & S & S & S & S \\
C. parapsilosis & S & S & S & S-I & S-I \\
C. glabrata & S-DD to R & S-DD to R & S & S-I & S \\
C. krusei & R & S-DD to R & S & S to R & S \\
C. lusitaniae & S & S & S & S & S \\
C. kefyr & S & S & S & S-R & S \\
C. guilliermondii & S & S & S & S & S \\
C. dubliniensis & S & S & S &
\end{tabular}

2007; Andes et al. 2012]. In a recently published study by Andes and colleagues, a quantitative review of 1915 patients who were randomized into several clinical trials evaluating the treatment of invasive candidiasis were reviewed. Although numerous variables were evaluated, only two treatment-related factors, use of an echinocandin and the removal of the central venous catheter, were associated with an improved survival rate and greater clinical success [Andes et al. 2012]. However, patients who are infected with susceptible Candida spp. and are clinically stable can be readily transitioned to oral fluconazole or voriconazole to complete the recommended 14-day course after the blood cultures have been cleared. Initial therapy with an echinocandin is also preferred in patients infected with either C. glabrata or C. krusei. In patients who have initially received fluconazole and are clinically improving, and whose follow-up culture results are negative, continuing use of an azole is reasonable [Pappas et al. 2009]. For infections due to C. parapsilosis, initial treatment with fluconazole is recommended nonetheless if a patient has initially received an echinocandin and is clinically improved, continued use of an echinocandin is reasonable. If an echinocandin is not available and either C. glabrata or C. krusei are suspected, initial therapy with voriconazole $6 \mathrm{mg} / \mathrm{kg}$ twice daily followed by $3 \mathrm{mg} / \mathrm{kg}$ twice daily is reasonable [Kullberg et al. 2005]. Other alternatives may also include AmB-d $0.5-1.0 \mathrm{mg} / \mathrm{kg}$ daily or LFAmB $3-5 \mathrm{mg} / \mathrm{kg}$ daily.

Management of invasive candidiasis in patients with neutropenia may include an echinocandin, LFAmB 3-5 mg/kg/day or voriconazole $(6 \mathrm{mg} / \mathrm{kg}$ administered intravenously twice daily for two doses, then $3 \mathrm{mg} / \mathrm{kg}$ twice daily) [Pappas et al. 2009]. Fluconazole $400 \mathrm{mg} /$ day may also be an alternative.
Successful therapy for serious systemic Candida infections requires starting antifungal therapy as early as possible. Therapy should be initiated as soon as adequate cultures have been obtained. Despite the newer advances in the diagnosis and newer antifungals, mortality rates for candidemia and disseminated candidiasis have not improved markedly over the past decade and remain in the range of $30-40 \%$.

Antifungal prophylaxis of invasive candidiasis in patients who are in the high-risk group is currently recommended in several situations, which include patients with chemotherapy-induced neutropenia: fluconazole $400 \mathrm{mg}$ daily, posaconazole $200 \mathrm{mg}$ three times per day, or caspofungin $50 \mathrm{mg}$ daily is recommended during induction chemotherapy for the duration of neutropenia [Viscoli et al. 1999; Husain et al. 2006; Ullmann and Cornely, 2006; van Burik et al. 2004]. In HSCT recipients, primarily those with allogeneic transplants, fluconazole $400 \mathrm{mg}$ daily, or posaconazole $200 \mathrm{mg}$ three times daily, or micafungin $50 \mathrm{mg}$ daily is recommended during the period of neutropenia. In SOT recipients, fluconazole $200-400 \mathrm{mg}$ daily or LFAmB $1-2 \mathrm{mg} / \mathrm{kg}$ daily for at least $7-14$ days is recommended as postoperative prophylaxis for highrisk liver, pancreas, and small bowel transplant recipients.

Posaconazole has been shown to be effective prophylaxis against IFIs in high-risk patients with neutropenia and HSCT recipients, but its role as empirical therapy for candidiasis has not been established.

Empiric therapy. Empiric use of antifungal agents in patients who are febrile is widespread without much supporting data [Pappas, 2006, Leleu et al. 2002]. A major pitfall has been in 
Table 6. Distribution of fungal pathogens causing invasive fungal infections in transplant recipients.

\begin{tabular}{llllllll}
\hline \multirow{7}{*}{ IFI pathogen } & \multicolumn{7}{l}{ Type of transplantation } \\
\cline { 2 - 8 } & HSCT (\%) & Kidney (\%) & Liver (\%) & Lung (\%) & Pancreas (\%) & Heart (\%) & Intestine (\%) \\
\hline Aspergillus & $43-64$ & $11-14$ & $7-11$ & $44-63$ & $5-10$ & $23-25$ & 0 \\
Mucorales & $5-8$ & $1-2$ & $2-3$ & $2-3$ & 0 & $2-3$ & 0 \\
Fusarium & $2-3$ & 0 & 0 & $<1$ & 0 & 0 & 0 \\
Other mold & $3-7$ & $2-3$ & $0-2$ & $9-20$ & $3-5$ & $2-7$ & 0 \\
Candida & $22-28$ & $49-61$ & $68-79$ & $23-24$ & 76 & $49-65$ & 85 \\
\hline Neofytos et al. [2009]; Kontoyiannis et al. [2010]; Pappas et al. [2010]. & & \\
IFI, invasive fungal infection; HSCT, hematopoietic stem cell transplantation.
\end{tabular}

establishing the definitive diagnosis of invasive candidiasis in the setting of negative blood cultures. It appears reasonable to initiate empiric antifungal therapy in selected patients with known risk factors. Echinocandins with their broad spectrum of activity and improved efficacy may be preferable, although less expensive fluconazole may also be an alternative. Some criteria for initiating empiric antifungal therapy include patients with known risk factors for candidiasis, patients who are febrile and on broadspectrum antibiotics for over $96 \mathrm{~h}$, and patients with multifocal Candida colonization.

\section{Invasive mold infections}

Invasive mold infections (IMIs) have become an important cause of morbidity and mortality in HSCT and SOT recipients. Evolving transplant modalities and techniques, immunosuppressive strategies, and the use of antifungal prophylaxis has impacted the epidemiology and temporal pattern of IFIs in this population [Neofytos et al. 2009; Kontoyiannis et al. 2010; Pappas et al. 2010].

\section{Epidemiology}

Although Candida spp. remain the most common cause of IFIs in transplant recipients, molds account for approximately $40 \%$ of IFIs in the transplant population [Kontoyiannis et al. 2010; Pappas et al. 2010]. Recently, the TransplantAssociated Infection Surveillance Network (TRANSNET) reported prospectively collected data between 2001 and 2006, on 983 IFIs in 875 HSCT recipients and 1208 IFIs in 1063 SOT recipients [Kontoyiannis et al. 2010; Pappas et al. 2010]. The distribution of fungal pathogens causing IFIs in the HSCT and SOT populations identified in this large multicenter study is shown in Table 6. In this report IMIs occurred mostly in HSCT recipients and accounted for $57 \%$ of IFIs among HSCT recipients, and $27 \%$ in SOT recipients, whereas Candida infections predominated in the SOT population. The comparative increased frequency of molds causing IFIs in the HSCT population is likely the consequence of greater numbers of human leukocyte antigen (HLA)mismatched or unrelated HSCTs being performed, with a higher risk for graft versus host disease (GVHD), requiring more intense immunosuppression, as well as the widespread use of anti-Candida prophylaxis [Park et al. 2011]. Aspergillus spp. accounted for the majority of mold infections, $76 \%$ among HSCT recipients and $81 \%$ among SOT recipients [Kontoyiannis et al. 2010; Pappas et al. 2010]. Aspergillus fumigatus was the predominant Aspergillus spp., followed by $A$. terreus, $A$. niger and $A$. flavus. Mucorales was the next most common mold infection and occurred in $14 \%$ and $10 \%$ in HSCT and SOT recipients, respectively [Kontoyiannis et al. 2010; Pappas et al. 2010; Park et al. 2011]. Among the Mucorales, Rhizopus, Mucor and Rhizomucor were the most common species recovered. The other non-Aspergillus molds recovered primarily in the HSCT population included Fusarium and Scedosporium [Park et al. 2011]. Several studies have also reported the emergence of Fusarium and Scedosporium in the transplant population [Campo et al. 2010; Nucci et al. 2003; Ben-Ami et al. 2009; RodriguezTudela et al. 2009; Musk et al. 2006; Farina et al. 2006; Lamaris et al. 2006; Husain et al. 2003, 2005; Maertens et al. 2000]. F. solani was the predominant Fusarium spp., whereas $S$. apiospermum and $S$. prolificans were the most common Scedosporium spp. [Park et al. 2011].

Non-Aspergillus molds have been increasing in transplant recipients and have implications for therapy since they exhibit a variable susceptibility 
profile to the commonly used antifungals. For example, the Mucorales are intrinsically resistant to voriconazole yet remain susceptible to $\mathrm{AmB}$ and posaconazole. Fusarium spp. have variable susceptibilities to antifungals, as such $F$ solani, which tends to be resistant to azoles and have higher MICs than the polyenes [Nucci and Anaissie, 2007]. The triazoles voriconazole and posaconazole appear to have superior in vitro activity against Scedosporium spp. than AmB.

In the SOT population, the highest rate of IFIs was seen in small bowel transplants, followed by heart-lung, liver, pancreas, heart, and kidney transplants [Kontoyiannis et al. 2010]. Allogeneic HSCT recipients, especially unrelated or mismatched transplants, had a fivefold greater risk for IFIs compared with autologous HSCT recipients [Pappas et al. 2010]. Despite a slight increase in the incidence of all IFIs during 2002-2005, there was no significant increase in the incidence of mold infections in either the SOT or HSCT populations over the past decade. In contrast, there appears to be a comparative increase in the incidence of mucormycosis [Park et al. 2011; Kontoyiannis and Lewis, 2006; Petrikkos et al. 2012]. This increase may be a consequence of a greater number of at-risk patients undergoing HSCT or SOT, the use of more aggressive immunosuppressive treatments for GVHD and rejection, and possibly the increased use of voriconazole for antifungal prophylaxis or for empiric therapy [Kontoyiannis et al. 2006; Petrikkos et al. 2012;
Trifilio et al. 2007; Spellberg et al. 2012; Xhaard et al. 2012, Lanternier et al. 2012].

The comparative distribution of IMIs varies among the type of organ transplanted (Table 6). Overall, invasive aspergillosis (IA) and other mold infections predominated among HSCT recipients. Among SOT recipients IA was most common in lung transplant recipients, accounting for $44 \%$ of all IFIs compared with $23 \%, 14 \%$, $11 \%$, and $5 \%$ in heart, kidney, liver, and pancreas transplant recipients respectively [Pappas et al. 2010].

The timing of IFIs after HSCT and SOT has also been evaluated in several prospective multicenter studies (Table 7) [Neofytos et al. 2009, 2010; Kontoyiannis and Lewis, 2006; Park et al. 2011]. The median time to the diagnosis of IA in HSCT recipients is 82-99 days compared with 184-400 days in SOT recipients [Neofytos et al. 2009; Kontoyiannis and Lewis, 2006; Park et al. 2011]. Mucormycosis, fusariosis and other IMIs tend to occur even later after transplantation (Table 7). The shift of IA and other IMIs in HSCT patients to the late post-transplant period has been noted in several studies [Park et al. 2011; Ben-Ami et al. 2009]. Similarly, the late occurrence of IMIs caused by Aspergillus and non-Aspergillus molds in SOT recipients has also been reported [Husain et al. 2005; Singh et al. 2003, 2006]. In HSCT recipients, the shift in IMIs from early in the neutropenic pre-engraftment period to later during the period of GVHD

Table 7. Incidence, timing and outcomes of invasive fungal infection after transplantation.

\begin{tabular}{lll}
\hline Incidence, timing and outcomes of IFI & HSCT & SOT \\
\hline 1-year incidence of IFI laverage of studies) (\%) & & 0.7 \\
Aspergillus IFI & 1.6 & 0.2 \\
Mucorales IFI & $<0.3$ & 0.2 \\
Other mold IFI & $<0.3$ & 1.9 \\
Candida IFI & 1.1 & 184 \\
Median time to IFI after transplant (days) & 99 & 312 \\
Aspergillus IFI & 135 & - \\
Mucorales IFI & 123 & 467 \\
Fusarium IFI & - & 103 \\
Other mold IFI & 61 & 59 \\
Candida IFI & & - \\
12-month survival after IFI (\%) & 25.4 & 61 \\
Aspergillus IFI & 6.3 & 66 \\
Fusarium IFI & 28 \\
Other mold IFI & 33.6 & \\
Candida IFI & & \\
\hline Neofytos et al. [2009]; Kontoyiannis et al. [2010]; Pappas et al. [2010]. \\
IFI, invasive fungal infection; HSCT, hematopoietic stem cell transplantation; SOT, solid organ transplantation.
\end{tabular}


may be the consequence of the increasing use of reduced intensity nonmyeloablative conditioning regimens and peripheral blood stem cells, resulting in shorter periods of neutropenia as well as the use of antifungal prophylaxis during the early post-HSCT period [Park et al. 2011; Nucci and Anaissie, 2009].

\section{Risk factors}

Several studies have examined the risk factors associated with the development of IMIs in transplant recipients (Table 8). In HSCT recipients, the duration of profound neutropenia remains an important risk factor for early onset IMIs. The use of cord blood as the source of donor cells is also an additional risk factor for early IA [Park et al. 2011]. However, GVHD and its treatment are the key factors that contribute to the increased risk for late-onset IMIs. The increased use of unrelated and HLA mismatched donors, prolonged corticosteroids, immunomodulators, such as infliximab and alemtuzumab may also increase the risk of IA [Park et al. 2011; Safdar et al. 2010]. Prolonged neutropenia and the prolonged use of corticosteroids have also been associated with an increased risk of IMIs due to Mucorales, Fusarium, and Scedosporium in HSCT recipients [Neofytos et al. 2009; Kontoyiannis and Lewis, 2006; Park et al. 2011; Dignani and Anaissie, 2004; Nucci and Anaissie, 2006; Nucci, 2003].

In SOT recipients, the risk factors for IMIs are strongly associated with end-organ failure,

Table 8. Risk factors for invasive mold infections in transplant recipients.

\begin{tabular}{|c|c|c|c|c|}
\hline \multirow[t]{2}{*}{ Type of transplant } & \multicolumn{4}{|c|}{ Risk factors associated with invasive mold infections caused by } \\
\hline & Aspergillus & Mucorales & Fusarium & Scedosporium \\
\hline \multirow[t]{11}{*}{ HSCT } & Older age & Neutropenia & Neutropenia & Neutropenia \\
\hline & Allogeneic HSCT & Severe GVHD & Severe GVHD & Severe GVHD \\
\hline & MUD and MMRD HSCT & Corticosteroids & Corticosteroids & Corticosteroids \\
\hline & T-cell depleted graft & Older age & Myeloma & \\
\hline & Cord blood grafts & Diabetes mellitus & & \\
\hline & Neutropenia & CMV disease & & \\
\hline & Severe GVHD & Malnutrition & & \\
\hline & Corticosteroid & Myelodysplasia & & \\
\hline & Alemtuzumab, infliximab & Voriconazole exposure & & \\
\hline & CMV disease & & & \\
\hline & TLR4 haplotype in donor & & & \\
\hline \multicolumn{5}{|c|}{ 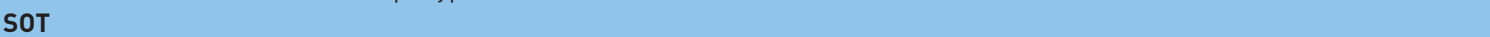 } \\
\hline \multirow[t]{3}{*}{ Kidney } & Corticosteroids & Renal failure & & \\
\hline & Antirejection therapy & Diabetes mellitus & & \\
\hline & Renal failure requiring dialysis & Liver transplant & & \\
\hline \multirow[t]{6}{*}{ Liver } & Retransplant & with iron overload & & \\
\hline & Renal failure requiring dialysis & Voriconazole exposure & & \\
\hline & Reoperation & Caspofungin exposure & & \\
\hline & Prolonged ICU stay & & & \\
\hline & Corticosteroids & & & \\
\hline & CMV and HHV 6 infection & & & \\
\hline \multirow[t]{6}{*}{ Lung } & Aspergillus colonization & & & \\
\hline & Single-lung transplant & & & \\
\hline & Anastomotic complications & & & \\
\hline & Graft ischemia & & & \\
\hline & Antirejection therapy & & & \\
\hline & CMV disease & & & \\
\hline \multirow[t]{4}{*}{ Heart } & Aspergillus colonization & & & \\
\hline & Renal failure requiring dialysis & & & \\
\hline & Reoperation & & & \\
\hline & CMV disease & & & \\
\hline \multicolumn{5}{|c|}{$\begin{array}{l}\text { Park et al. [2011]; Petrikkos et al. [2012]; Trifilio et al. [2007], Spellberg et al. [2012]; Safdar et al. [2010]; Fortún et al. } \\
\text { [2012]; Silveira and Husain [2007]; Singh et al. [2003]; Husain [2009]; Ibrahim et al. [2011]. } \\
\text { CMV, cytomegalovirus; GVHD, graft versus host disease; HSCT, hematopoietic stem cell transplantation; ICU, intensive } \\
\text { care unit; MUD, matched unrelated donor; MMRD, mismatched related donor; TLR4, toll-like receptor 4; SOT, solid organ } \\
\text { transplantation. }\end{array}$} \\
\hline
\end{tabular}


especially renal or hepatic insufficiency [Nucci, 2003; Fortún et al. 2012; Silveira and Husain, 2007]. A study from Spain reported a 29-fold higher risk of IA in liver transplant recipients who required retransplantation and a 24 -fold higher risk in patients requiring dialysis after transplantation [Fortún et al. 2012]. Lung transplant recipients who have documented prior colonization with Aspergillus or those with anastomotic complications have a greater risk of post-transplant Aspergillus tracheobronchitis or pulmonary IA. Renal transplant recipients receiving prolonged corticosteroids or antirejection therapy with sirolimus were also reported to be at higher risk of developing IA. A higher risk of mucormycosis was also reported in SOT recipients with diabetes and prior exposure to either voriconazole or caspofungin [Petrikkos et al. 2012]. An understanding of the specific risk factors in the various types of SOT and HSCT and the identification of high-risk transplant recipients is essential to guide effective empiric and preventive antifungal strategies [Neofytos et al. 2009; Singh et al. 2003; Silveira and Husain, 2007].

\section{Clinical features}

The clinical features of IMIs are frequently nonspecific. Although most IMIs cause pulmonary infection, infections may also involve the paranasal sinuses, the central nervous system (CNS), the skin, the gastrointestinal tract or occasionally they can become disseminated (Figure 1). Table 6 summarizes the frequency of the organ sites involved in IMIs in transplant recipients.

Aspergillus can cause a wide spectrum of disease in humans. Fever is a common, but nonspecific

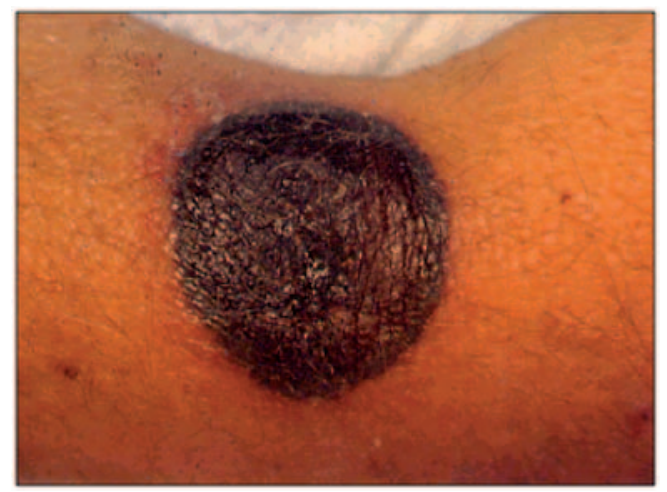

Figure 1. Cutaneous lesion of aspergillosis. Reproduced with permission from Dr Pranatharthi Chandrasekar. symptom [Nucci, 2003]. Involvement of the respiratory tract occurs in over $60 \%$ of patients, and thus, about $50 \%$ of the patients present with respiratory symptoms, including cough, dyspnea and pleuritic chest pain [Nucci, 2003]. Sinus infection can result in facial and orbital pain, along with localized edema. Infections of the CNS can present as altered mentation or focal neurological deficits. Given the angioinvasive nature of Aspergillus spp., the symptoms of lung and brain involvement can resemble either a pulmonary embolism or a stroke. In SOT recipients, IA tends to be localized to the lungs. The manifestations of IA in the lung and heart-lung transplant recipients are frequently different from the pulmonary infection in other transplants. Infections at the anastomotic site and ulcerative tracheobronchitis are the most common pulmonary infections reported. In addition, endobronchial stent obstruction, bronchial plugging and pneumonitis may also be seen [Singh and Husain, 2003; Husain, 2009]. Interestingly enough, both CNS and disseminated disease have declined in recent years [Singh and Husain, 2003]. The factors resulting in the lower incidence of CNS and disseminated disease are yet to be elucidated. Recent reports suggest that the current use of calcineurin and TOR (target of rapamycin) inhibitors in antirejection regimens may have a beneficial antifungal effect [Singh and Husain, 2003].

Infections due to Mucorales often cause localized infections such as sinonasal, sino-orbital or rhinocerebral disease. Occasionally, involvement of the lung, gastrointestinal tract, skin and disseminated disease may be seen [Petrikkos et al. 2012; Lanternier et al. 2012]. Typical symptoms may include facial pain and swelling, orbital pain, proptosis, visual loss and opthalmoplegias. Given the propensity of Mucorales to cause invasion of the blood vessels, the infection is characterized by the development of necrotic lesions in the oral, nasal or sinus mucosa. The infection may progress rapidly and can invade the CNS, causing stroke-like symptoms [Kontoyiannis and Lewis, 2006; Lanternier et al. 2012; Ibrahim et al. 2011, 2012]. When dissemination to the skin occurs it is characterized by the development of rapidly progressive cutaneous necrosis.

Although IMIs caused by Fusarium and Scedosporium in HSCT recipients generally affect the lungs, unlike infections caused by 
Aspergillus or Mucorales, dissemination to the skin structures occurs in up to $70 \%$ of cases. In the case of Fusarium spp., the propensity for dissemination via the bloodstream often results in high rates of isolation from blood cultures $(\sim 70 \%)$ [Nucci et al. 2004; Maertens et al. 2000; Nucci and Anaissie, 2006].

\section{Diagnosis and management of mold infection}

EORCT/MSG definitions. The European Organization for Research and Treatment of Cancer/ Invasive Fungal Infections Cooperative Group (EORTC) and the National Institute of Allergy and Infectious Diseases Mycoses Study Group (MSG) have developed standard definitions for IFIs based on the level of probability in the diagnosis of IFIs occurring in immunocompromised patients [De Pauw et al. 2008]. Classically, IFIs have been divided into three categories: proven, probable, and possible based on host factors, clinical manifestations and mycological evidence.

Microbiologic criteria for the diagnosis of proven IFIs rely on direct tests (cytology, direct microscopy and culture) demonstrating the presence of fungal elements [De Pauw et al. 2008]. However, obtaining tissue samples or performing invasive procedures is not always feasible because of cytopenias or the poor clinical condition of these patients. Thus, the initiation of appropriate antifungal therapy is frequently delayed. The difficulty in establishing an early diagnosis is one of the primary reasons for the high mortality rates seen in IMIs [Chamilos et al. 2006; Rinaldi 1991; von Eiff et al. 1995].

Nonculture diagnostic assays such as the galactomannan (GM) and BG for the diagnosis of IFIs have been developed over the last two decades [Boudewijins et al. 2006; Mennik-Kersten and Verweij, 2006]. The advent of these indirect tests represents a major advance in the management of patients at risk for IFIs (Table 3 ).

Galactomannan assay. GM is an Aspergillus-specific polysaccharide residue that is incorporated into the cell wall during the initial phase of fungal growth. Eventually, GM is released into the circulation and possibly reused as a source of nutrient for further growth [Mennik-Kersten et al. 2004].

Table 9. Organ involvement in invasive mold infections among transplant recipients.

\begin{tabular}{|c|c|c|c|c|}
\hline Organ involved & Aspergillus (\%) & Mucorales (\%) & Fusarium (\%) & Scedosporium (\%) \\
\hline \multicolumn{5}{|l|}{ HSCT } \\
\hline Lung & 74-93 & 52 & 7 & 40 \\
\hline Sinus & 4 & 21 & 7 & NA \\
\hline Central nervous system & $4-6$ & 14 & NA & 36 \\
\hline Skin & NA & 9 & 36 & 38 \\
\hline Gastrointestinal tract & NA & 2 & NA & NA \\
\hline Fungemia & NA & NA & 28 & 25 \\
\hline Disseminated infection & $13-16$ & 10 & 75 & 69 \\
\hline \multicolumn{5}{|l|}{ SOT } \\
\hline Lung & 91 & $24-56$ & & 46 \\
\hline Sinus & NA & $15-22$ & & 2 \\
\hline Central nervous system & 7 & $14-16$ & & 25 \\
\hline Skin & NA & $13-22$ & 63 & 32 \\
\hline Gastrointestinal tract & NA & $7-12$ & NA & NA \\
\hline Fungemia & NA & NA & NA & 16 \\
\hline Disseminated infection & $11-22$ & $9-26$ & 22 & 55 \\
\hline \multicolumn{5}{|l|}{$\begin{array}{l}\text { Disseminated infection } \\
\text { in specific SOT }\end{array}$} \\
\hline Kidney & $9-36$ & $9-13$ & & \\
\hline Liver & $50-60$ & $26-55$ & & \\
\hline Lung & $15-20$ & $11-25$ & & \\
\hline Heart & $20-35$ & $11-20$ & & \\
\hline \multicolumn{5}{|c|}{$\begin{array}{l}\text { Neofytos et al. [2009]; Kontoyiannis et al. [2010]; Pappas et al. [2010]; Park et al. [2011]; Nucci et al. [2004]; Petrikkos et al. } \\
\text { [2012]; Rodriguez-Tudela et al. [2009]; Lamaris et al. [2006]; Nucci and Anaissie [2007]; Trifilio et al. [2007]; Lanternier } \\
\text { et al. [2012]; Safdar et al. [2010]; Fortún et al. [2012]; Silveira and Husain [2007]; Singh et al. [2003]; Husain [2009]; } \\
\text { Ibrahim et al. [2011]. } \\
\text { Data tabulated and averages used from the studies. } \\
\text { HSCT, hematopoietic stem cell transplant; SOT, solid organ transplantation; NA, not available. }\end{array}$} \\
\hline
\end{tabular}


In the clinical setting, the detection of serum GM antigen has been shown to be a useful screening test for the early diagnosis of IA in patients at risk [Maertens et al. 2001; Pfeiffer et al. 2006; Sulahian et al. 2001]. Serum is the most frequently tested specimen and appears to provide the highest sensitivity (up to $95 \%$, depending on the patient population and previous antifungal therapy) [Chamilos et al. 2006]. Galactomannan is water soluble and therefore can be detected in specimens other than serum, including bronchoalveolar lavage (BAL), cerebrospinal fluid, pleural fluid and urine [Klont et al. 2004]. Except for serum and BAL, the use of GM in other specimens remains investigational.

A recent meta-analysis study was conducted to determine the role of BAL-GM in the diagnosis of IA. In this study, BAL-GM sensitivity and specificity varied from $84 \%$ and $95 \%$, respectively, depending on the population tested and the cutoff used [Zou et al. 2012]. BAL-GM may be used as an adjunctive tool in establishing the diagnosis of IA (see http://www.accessdata.fda.gov/ cdrh_docs/pdf6/K060641.pdf and http://www.accessdata.fda.gov/cdrh_docs/pdf9/K093678.pdf).

Typically, a serum GM value of at least 0.5 is considered positive. Using this suggested cutoff point, the reported sensitivity and specificity of the GM assay was $80.7 \%$ and $89.2 \%$ respectively [Chamilos et al. 2006]. Conversely, due to the lack of data, the threshold for positive BALGM remains under debate.

The use of serum GM is also an excellent tool for the early diagnosis of IA. Sulahian and colleagues showed that GM might be detected in serum as early as 5-8 days before the clinical manifestations of IA develop [Sulahian et al. 2001]. These results support the use of GM as a screening tool for patients at high risk of developing IA. In this setting, the detection of positive results, particularly in two consecutive serum samples, provides strong support for the diagnosis of IA [von Eiff et al. 1995; Mennick-Kersten and Verweij, 2006; Maertens et al. 2001]. Recently, some authors have also suggested that GM could serve as a surrogate marker of clinical response to treatment in patients with IA [Miceli et al. 2008; Park et al. 2011; Maertens et al. 2009; Boutboul et al. 2002]. Several studies showed that the titer of GM tends to decrease in cases that demonstrated a clinical response. Similarly, increasing GM titers were associated with poor outcomes [Park et al. 2011; Maertens et al. 2009;
Boutboul et al. 2002; Woods et al. 2007; Segal et al. 2008]. False-positive reactions have also been reported in $1-18 \%$ of the tested samples and may be due to cross reactivity or false-positive GM (Table 3).

Radiographic imaging. Radiographs of the chest and sinuses have been used as a primary means of diagnostic assessment. However, they are frequently inadequate to establish a diagnosis. Initial chest computed tomography (CT) scan findings in IA are dominated by the nodule and its associated 'halo sign'. The main finding in IA is generally a pulmonary nodule greater than 1 $\mathrm{cm}$ in diameter, that is, the mancronodule. It is defined as a localized, space-occupying, ovoid, soft-tissue opacity that displaces rather than conforms to the shape of the preexisting aerated lung [Georgiadou et al. 2011]. More than 90\% of patients with mycologically proven IA have at least one pulmonary nodule. The halo sign apparent on the CT scan is a modifier of the macronodule. It is defined as a perimeter of ground-glass lung opacity surrounding a pulmonary nodule. On initial CT scan, a study of patients with mycologically proven IA, about $33 \%$ have one or more macronodules with a halo sign. The 'air crescent sign' generally follows the halo sign approximately 1 week later (Figure 2).

\section{Management}

Despite the advances in the field and the advent of newer technologies, identification of fungal pathogens continues to be difficult and early diagnosis is not always possible [Georgiadou

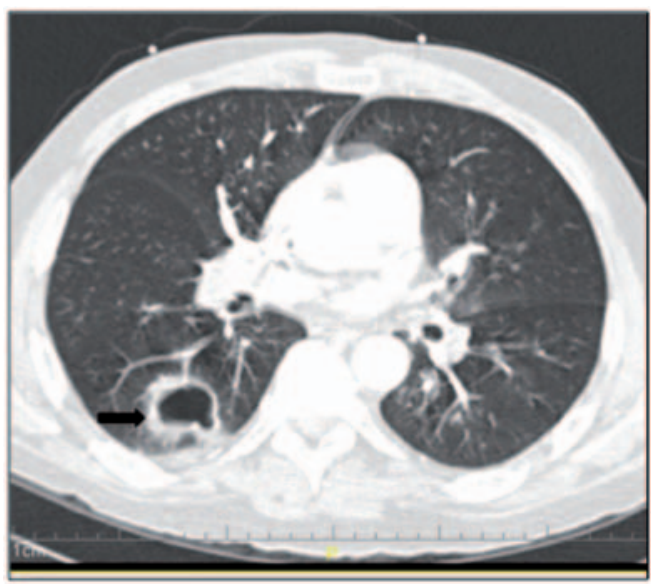

Figure 2. Computed tomography scan showing necrotic nodular infiltrate in a hematopoietic stem cell transplant recipient with pulmonary aspergillosis. 
et al. 2011; Miceli and Lee, 2011; Revankar and Sutton, 2010]. Because early treatment is crucial in the management of these patients, initiation of empiric antifungal therapy is not uncommon when IFI is suspected [Walsh et al. 2008].

Strategies for the management of mold infections. Current strategies for the management of IFIs include prophylaxis, empiric, preemptive, and targeted therapy (Figure 3) [Ruhnke et al. 2012; Freifeld et al. 2011]. Antifungal prophylaxis involves the administration of an antifungal drug to high-risk patient populations before the onset of signs or symptoms of infection. In addition to neutropenia during the pre-engraftment period in HSCT recipients, these patients are at high-risk for mold infection as a consequence of severe cellmediated immunodeficiency due to GVHD and its therapy (Table 8). Similarly, certain SOT recipients are also at high risk for mold infections (Table 8). Prophylaxis with anti-mold agents has been recommended in these select patient groups [Tomblyn et al. 2009; Singh et al. 2013].
In this setting, the antifungal agent is started despite the fact that adequate microbiological diagnosis of IFIs is unavailable [Freifeld et al. 2011]. Preemptive therapy is often initiated when nonspecific radiographic signs are present or laboratory tests are suggestive of IMIs, in the absence of microbiological or histopathological confirmation of IFIs. Although preemptive antifungal therapy has been used successfully in patients with neutropenia who are febrile, there are no standard recommendations that fully support its use [Pasqualotto and Colombo, 2010; Kontoyiannis and Lewis, 2011; Lortholary et al. 2010]. Targeted therapy relies on treating microbiologically and histologically documented cases of IFIs [Ruhnke et al. 2012; Freifeld et al. 2011].

Specific management issues. Specific antifungals used for the treatment of IFI are summarized in Table 4. The management and prognosis of IA depends on the specific form of disease and the degree of immunosuppression. For over 50 years, AmB-d was the mainstay of antifungal therapy. Guidelines for the management of IA have been

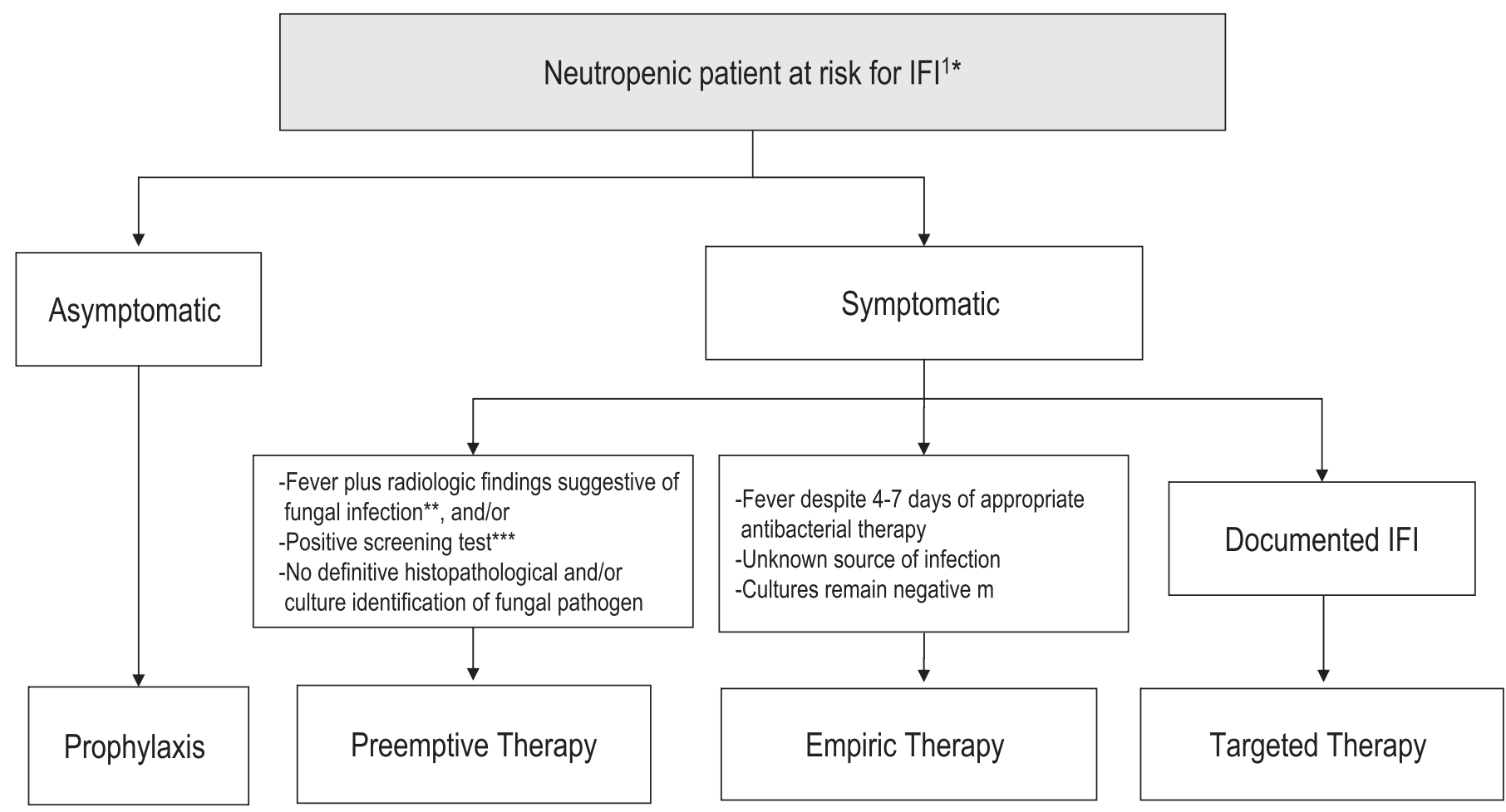

References:

1 Patient at risk for IFI include prolonged neutropenia after intense chemotherapy for hematologic malignancy, and high-risk HSCT and SOT recipients

'IFI: invasive fungal infection;

"Radiologic findings suggestive of IFI include high resolution computed tomography scan of the thorax showing new $\geq 1 \mathrm{~cm}$ single or multiple nodules with or without halo sign, lobar consolidation, wedge-shaped consolidative infarct.

"'Screening tests include Aspergillus galactomannan, 1,3 beta-D-glucan, and /or PCR

Figure 3. Strategies for the Management of Neutropenic Patients at High Risk for Invasive Fungal Infections. 
published by the Infectious Diseases Society of America [Walsh et al. 2008]. The current mainstay of therapy for IA is considered to be voriconazole. A randomized, multicenter study compared AMB-d with voriconazole as initial therapy for IA. This pivotal study demonstrated that initial therapy with voriconazole led to better responses and improved survival with fewer serious side effects, such as renal insufficiency and infusion-related toxicity [Pasqualotto and Colombo, 2010]. The appropriate dose of voriconazole is $6 \mathrm{mg} / \mathrm{kg}$ twice daily for 1 day, followed by $4 \mathrm{mg} / \mathrm{kg}$ twice daily.

A crucial factor in optimizing therapy in any patient with IA is the decrease or elimination of the immunosuppressant whenever possible. The recent literature suggests that if patients are diagnosed and treated early with appropriate antifungal therapy, the response rates may reach $50 \%$ or greater [Ruhnke et al. 2012].

Successful treatment of mucormycosis requires a high index of clinical suspicion for an early diagnosis [Kontoyiannis and Lewis, 2006; Ibrahim et al. 2011; Freifeld et al. 2011]. Mortality rates as high as $85 \%$ have been documented. Treatment requires reversal of the underlying condition, when possible; wide and extensive surgical removal of the affected tissue; and early antifungal therapy. Unfortunately, prospective randomized clinical trials have not been performed. Current recommendations include high-dose LFAmB at doses of $7-10 \mathrm{mg} / \mathrm{kg} /$ day [Kontoyiannis and Lewis, 2006]. The optimal duration of therapy is unknown, but a total dose of 2-6 $\mathrm{g}$ has been used in some cases.

In addition, posaconazole has demonstrated in vitro activity against many agents of mucormycosis and may be used as step-down therapy in patients who have responded to initial therapy with LFAmB. Voriconazole has not been shown to be active in vitro, and neither have the echinocandin group of antifungals.

The overall prognosis of the infection depends on several factors, including the site of infection, the rapidity of diagnosis, and the type and severity of immunosuppression. Although the overall mortality rate for mucormycosis is approximately $50 \%$, the mortality rate for the rhinocerebral form is approximately $85 \%$.

Patient survival in patients with infections due to Fusarium spp. include the variable susceptibility of the different Fusarium spp. and the immunocompromised state of the patient [Ibrahim et al. 2012]. Fusarium spp. are intrinsically resistant to many of the azoles, and occasionally, AmB. Early open-label clinical trials and compassionate clinical trials have demonstrated that voriconazole shows excellent activity against all Fusarium spp. [Lortholary et al. 2010; Herbrecht et al. 2004]. Voriconazole is used at a dose of $6 \mathrm{mg} / \mathrm{kg}$ every $12 \mathrm{~h}$ for two doses, followed by $4 \mathrm{mg} / \mathrm{kg}$ every $12 \mathrm{~h}$. Utilization of voriconazole demonstrates an increased survival of approximately $40 \%$ compared with the historical $10 \%$ success rates seen with AmB. Studies using LFAmB at higher doses have also shown some promise. A report of the successful treatment of a Fusarium infection in a severely immunocompromised child demonstrated evidence of synergistic activity between $\mathrm{AmB}$ and rifampin when used together with granulocyte transfusions. Posaconazole has also shown activity against Fusarium. In a study of 23 patients with fusariosis, posaconazole demonstrated an overall success rate of $48 \%$ [Herbrecht et al. 2004]. As with all IFIs, the successful treatment depends on the host's immune response, the early diagnosis and the early initiation of appropriate antifungal therapy. If possible, immunosuppression should be stopped or reduced and by the correction of neutropenia with growth factors. Unfortunately, prognosis remains poor with disseminated disease but correlates with the resolution of neutropenia.

The successful management of invasive scedosporiosis also depends on the early diagnosis and the early initiation of appropriate antifungal therapy, as well as the correction of the host's immune status [Musk et al. 2006; Husain et al. 2005]. If possible, immunosuppression should be either discontinued or reduced and the neutropenia reversed. Although clinical studies have not yet been performed, voriconazole is the drug of choice in the treatment of infections due to $S$. apiospermum [Troke et al. 2008]. Successful outcomes have also been reported in several cases of $S$. apiospermum infection when posaconazole was used as salvage therapy [Troke et al. 2008; Cortez et al. 2008]. Combination antifungal therapy with $\mathrm{AmB}$ and caspofungin or voriconazole and caspofungin has also shown promise in vitro [Musk et al. 2006]. However, prognosis remains poor with disseminated disease, but correlates with the resolution of neutropenia [Cortez et al. 2008]. 


\section{Conclusion}

Invasive fungal diseases have become an infection of increasing importance in the transplant recipient. Recent advances in antifungal therapy, such as the echinocandins, voriconazole and posaconazole have made a significant impact on the selection of antifungals due to their broader spectrum of activity, their excellent safety profile, and their ease of use in these critically ill, severely immunosuppressed patients. Additionally, the earlier recognition of the high-risk patient and the known difficulty in establishing a definitive diagnosis warrant the use of early antifungal therapy in an attempt to decrease the exceedingly high morbidity and mortality associated with these infections.

\section{Funding}

This research received no specific grant from any funding agency in the public, commercial, or notfor-profit sectors.

\section{Conflict of interest statement}

The authors declare no conflicts of interest in preparing this article.

\section{References}

Alexander, B. and Pfaller, M. (2006) Contemporary tools for the diagnosis and management of invasive mycoses. Clin Infect Dis 43: S15-S27.

Andes, D., Safdar, N., Baddley, J., Playford, G., Reboli, A., Rex, J. et al. (2012) Impact of treatment strategy on outcomes in patients with candidemia and other forms of invasive candidiasis: a patient-level quantitative review of randomized trials. Clin Infect Dis 54: $1110-1122$.

Ben-Ami, R., Lewis, R. and Kontoyiannis, D. (2009) Invasive mould infections in the setting of hematopoietic cell transplantation: current trends and new challenges. Curr Opin Infect Dis 22: 376-384.

Ben-Ami, R., Lewis, R., Raad, I. and Kontoyiannis, D. (2009) Phaeohyphomycosis in a tertiary care cancer center. Clin Infect Dis 48: 1033-1041.

Boudewijns, M., Verweij, P. and Melchers, W. (2006) Molecular diagnosis of invasive aspergillosis: the long and winding road. Future Microbiol 1: 283-293.

Boutboul, F., Alberti, C., Leblanc, T., Sulahian, A., Gluckman, E., Derouin, F. et al. (2002) Invasive aspergillosis in allogeneic stem cell transplant recipients: increasing antigenemia is associated with progressive disease. Clin Infect Dis 34: 939-943.

Campo, M., Lewis, R. and Kontoyiannis, D. (2010) Invasive fusariosis in patients with hematologic malignancies at a cancer center: 1998-2009. F Infect 60: 331-337.

Chamilos, G., Luna, M., Lewis, R., Bodey, G., Chemaly, R., Tarrand, J. et al. (2006) Invasive fungal infections in patients with hematologic malignancies in a tertiary care cancer center: an autopsy study over a 15-year period (1989-2003). Haematologica 91: 986-989.

Chandrasekar, P. and Sobel, J. (2006) Micafungin: a new echinocandin. Clin Infect Dis 42: 1171-1178.

Charlier, C., Hart, E., Lefort, A., Ribaud, P., Dromer, F., Denning, D. et al. (2006) Fluconazole for the management of invasive candidiasis: where do we stand after 15 years? F Antimicrob Chemother 57: 384-410.

Colombo, A., Nucci, M., Park, B., Nouér, S., Arthington-Skaggs, B., da Matta, D. et al. (2006) Epidemiology of candidemia in Brazil: a nationwide sentinel surveillance of candidemia in eleven medical centers. F Clin Microbiol 44: 2816-2823.

Cornely, O., Lasso, M., Betts, R., Klimko, N., Vazquez, J., Dobb, G. et al. (2007) Caspofungin for the treatment of less common forms of invasive candidiasis. F Antimicrob Chemother 60: 363-369.

Cortez, K., Roilides, E., Quiroz-Telles, F., Meletiadis, J., Antachopoulos, C., Knudsen, T. et al. (2008) Infections caused by Scedosporium spp. Clin Microbiol Rev 21: 157-197.

De Pauw, B., Walsh, T., Donnelly, J., Stevens, D., Edwards, J., Calandra, T. et al. (2008) Revised definitions of invasive fungal disease from the European Organization for Research and Treatment of Cancer/Invasive Fungal Infections Cooperative Group and the National Institute of Allergy and Infectious Diseases Mycoses Study Group (EORTC/ MSG) Consensus Group. Clin Infect Dis 46: 1813-1821.

Dignani, M. and Anaissie, E. (2004) Human fusariosis. Clin Microbiol Infect 10(Suppl. 1): 67-75.

Eiland, E., Hassoun, A. and English, T. (2008) Points of concern related to the micafungin versus caspofungin trial. Clin Infect Dis 46: 640-641.

Farina, C., Gotti, E., Suter, F. and Goglio, A. (2006) Scedosporium apiospermum soft-tissue infection: a case report and review of kidney transplant literature. Transplant Proc 38: 1333-1335.

Fortún, J., Ruiz, I., Martín-Dávila, P. and CuencaEstrella, M. (2012) Fungal infection in solid organ recipients. Enferm Infecc Microbiol Clin 30(Suppl. 2): 49-56.

Freifeld, A., Bow, E., Sepkowitz, K., Boeckh, M., Ito, J., Mullen, C. et al. (2011) Clinical practice guideline for the use of antimicrobial agents in neutropenic patients with cancer: 2010 update by the IDSA. Clin Infect Dis 52: e56-e93.

Georgiadou, S., Sipsas, N., Marom, E. and Kontoyiannis, D. (2011) The diagnostic value of halo 
and reversed halo signs for invasive mold infections in compromised hosts. Clin Infect Dis 52: 1144-1155.

Herbrecht, R., Kessler, R., Kravanja, C., Meyer, M., Waller, J. and Letscher-Bru, V. (2004) Successful treatment of Fusarium proliferatum pneumonia with posaconazole in a lung transplant recipient. $\mathcal{F}$ Heart Lung Transplant 23: 1451-1454.

Husain, S. (2009) Unique characteristics of fungal infections in lung transplant recipients. Clin Chest Med 30: 307-313.

Husain, S., Alexander, B., Munoz, P., Avery, R., Houston, S., Pruett, T. et al. (2003) Opportunistic mycelial fungal infections in organ transplant recipients: emerging importance of non-Aspergillus mycelial fungi. Clin Infect Dis 37: 221-229.

Husain, S., Muñoz, P., Forrest, G., Alexander, B., Somani, J., Brennan, K. et al. (2005) Infections due to Scedosporium apiospermum and Scedosporium prolificans in transplant recipients: clinical characteristics and impact of antifungal agent therapy on outcome. Clin Infect Dis 40: 89-99.

Husain, S., Paterson, D., Studer, S., Pilewski, J., Crespo, M., Zaldonis, D. et al. (2006) Voriconazole prophylaxis in lung transplant recipients. $A m \mathcal{F}$ Transplant 6: 3008-3016.

Ibrahim, A., Edwards, J., Filler, S. and Spellberg, B. (2011) Mucormycosis and Entomophthoramycosis (zygomycosis), In: Kaufman, C., Pappas, P., Sobel, J. and Dismukes, W. (eds). Essentials of Clinical Mycology, 2nd edition edn, Oxford University Press: Oxford, pp. 265-280.

Ibrahim, A., Spellberg, B., Walsh, T. and Kontoyiannis, D. (2012) Pathogenesis of mucormycosis. Clin Infect Dis 54(Suppl. 1): S16-S22.

Kauffman, C. (2006) Clinical efficacy of new antifungal agents. Curr Opin Microbiol 9: 1-6.

Klont, R., Mennink-Kersten, M. and Verweij, P. (2004) Utility of Aspergillus antigen detection in specimens other than serum specimens. Clin Dis Infect 39: 1467-1474.

Kontoyiannis, D. and Lewis, R. (2006) Invasive zygomycosis: update on pathogenesis, clinical manifestations, and management. Infect Dis Clin North Am 20: $581-607$.

Kontoyiannis, D. and Lewis, R. (2011) How I treat mucormycosis. Blood 118: 1216-1224.

Kontoyiannis, D., Marr, K., Park, B., Alexander, B., Anaissie, E., Walsh, T. et al. (2010) Prospective surveillance for invasive fungal infections in hematopoietic stem cell transplant recipients, 2001-2006: overview of the Transplant-Associated Infection Surveillance Network (TRANSNET) Database. Clin Infect Dis 50: 1091-1100.

Kullberg, B., Sobel, J., Ruhnke, M., Pappas, P., Viscoli, C., Rex, J. et al. (2005) Voriconazole versus a regimen of amphotericin $\mathrm{B}$ followed by fluconazole for candidaemia in non-neutropenic patients: a randomised non-inferiority trial. Lancet 366: 1435-1442.

Kuse, E., Chetchotisakd, P., da Cunha, C., Ruhnke, M., Barrios, C., Raghunadharao, D. et al. (2007) Micafungin versus liposomal amphotericin B for candidaemia and invasive candidosis: a phase III randomised double-blind trial. Lancet 369: 1519-1527.

Lamaris, G., Chamilos, G., Lewis, R., Safdar, A., Raad, I. and Kontoyiannis, D. (2006) Scedosporium infection in a tertiary care cancer center: a review of 25 cases from 1989-2006. Clin Infect Dis 43: 1580-1584.

Lanternier, F., Sun, H., Ribaud, P., Singh, N., Kontoyiannis, D. and Lortholary, O. (2012) Mucormycosis in organ and stem cell transplant recipients. Clin Infect Dis 54: 1629-1636.

Leleu, G., Aegerter, P. and Guidet, B. (2002) Systemic candidiasis in intensive care units: a multicenter, matched-cohort study. F Crit Care 17: 168-175.

Lortholary, O., Obenga, G., Biswas, P., Caillot, D., Chachaty, E., Bienvenu, A. et al. (2010) French Mycoses Study Group. International retrospective analysis of 73 cases of invasive fusariosis treated with voriconazole. Antimicrob Agents Chemother 54: 4446-4450.

Maertens, J., Buve, K., Theunissen, K., Meersseman, W., Verbeken, E., Verhoef, G. et al. (2009)

Galactomannan serves as a surrogate endpoint for outcome of pulmonary invasive aspergillosis in neutropenic hematology patients. Cancer 115: 355-362.

Maertens, J., Lagrou, K., Deweerdt, H., Surmont, I., Verhoef, G., Verhaegen, J. et al. (2000) Disseminated infection by Scedosporium prolificans: an emerging fatality among haematology patients. Case report and review. Ann Hematol 79: 340-344.

Maertens, J., Verhaegen, J., Lagrou, K., Van Eldere, J. and Boogaerts, M. (2001) Screening for circulating galactomannan as a noninvasive diagnostic tool for invasive aspergillosis in prolonged neutropenic patients and stem cell transplantation recipients: a prospective validation. Blood 97: 1604-1610.

Mennink-Kersten, M., Donnelly, J. and Verweij, P. (2004) Detection of circulating galactomannan for the diagnosis and management of invasive aspergillosis. Lancet Infect Dis 4: 349-357.

Mennink-Kersten, M. and Verweij, P. (2006) Nonculture-based diagnostics for opportunistic fungi. Infect Dis Clin N America 20: 711-727.

Miceli, M. and Chandrasekar, P. (2012) Safety and efficacy of liposomal amphotericin B for the empirical therapy of invasive fungal infections in immunocompromised patients. Infection and drug resistance. Infect Drug Resist 5: 9-16.

Miceli, M., Grazziutti, M., Woods, G., Zhao, W., Kocoglu, M., Barlogie, B. et al. (2008) Strong correlation between serum Aspergillus galactomannan index and outcome of aspergillosis in patients with 
hematological cancer: clinical and research implications. Clin Infect Dis 46: 1412-1422.

Miceli, M. and Lee, S. (2011) Emerging moulds: epidemiological trends and antifungal resistance. Mycoses 54: e666-e678.

Moen, M., Lyseng-Williamson, K. and Scott, L. (2009) Liposomal amphotericin B: a review of its use as empirical therapy in febrile neutropenia and in the treatment of invasive fungal infections. Drugs 69: 361-392.

Morgan, J. (2005) Global trends in candidemia: review of reports from 1995-2005. Curr Infect Dis Rep 7: 429-439.

Morrell, M., Fraser, V. and Kollef, M. (2005) Delaying the empiric treatment of Candida bloodstream infection until positive blood culture results are obtained: potential risk factors for hospital mortality. Antimicrob Agents Chemother 49: 3640-3645.

Musk, M., Chambers, D., Chin, W., Murray, R. and Gabbay, E. (2006) Successful treatment of disseminated Scedosporium infection in 2 lung transplant recipients: review of the literature and recommendations for management. $\mathcal{F}$ Heart Lung Transplant 25: $1268-1272$.

Neofytos, D., Fishman, J., Horn, D., Anaissie, E., Chang, C., Olyaei, A. et al. (2010) Epidemiology and outcome of invasive fungal infections in solid organ transplant recipients. Transpl Infect Dis 12: $220-229$.

Neofytos, D., Horn, D., Anaissie, E., Steinbach, W., Olyaei, A., Fishman, J. et al. (2009) Epidemiology and outcome of invasive fungal infection in adult hematopoietic stem cell transplant recipients: analysis of Multicenter Prospective Antifungal Therapy (PATH) Alliance Registry. Clin Infect Dis 48: 265-273.

Nucci, M. (2003) Emerging moulds: Fusarium, Scedosporium and Zygomycetes in transplant recipients. Curr Opin Infect Dis 16: 607-612.

Nucci, M. and Anaissie, E. (2006) Emerging fungi. Infect Dis Clin North Am 20: 563-579.

Nucci, M. and Anaissie, E. (2007) Fusarium infections in immunocompromised patients. Clin Microbiol Rev 20: 695-704.

Nucci, M. and Anaissie, E. (2009) Fungal infections in hematopoietic stem cell transplantation and solid-organ transplantation - focus on aspergillosis. Clin Chest Med 30: 295-306.

Nucci, M., Anaissie, E., Queiroz-Telles, F., Martins, C., Trabasso, P., Solza, C. et al. (2003) Outcome predictors of 84 patients with hematologic malignancies and Fusarium infection. Cancer 98: 315-319.

Nucci, M., Marr, K., Queiroz-Telles, F., Martins, C., Trabasso, P., Costa, S. et al. (2004) Fusarium infection in hematopoietic stem cell transplant recipients. Clin Infect Dis 38: 1237-1242.
Odabasi, Z., Mattiuzzi, G., Estey, E. et al. (2004) Beta$\mathrm{D}$-glucan as a diagnostic adjunct for invasive fungal infections: validation, cutoff development, and performance in patients with acute myelogenous leukemia and myelodysplastic syndrome. Clin Infect Dis 39: 199-205.

Pappas, P. (2006) Invasive candidiasis. Infect Dis Clin North Am 20: 485-506.

Pappas, P., Alexander, B., Andes, D., Hadley, S., Kauffman, C., Freifeld, A. et al. (2010) Invasive fungal infections among organ transplant recipients: results of the Transplant-Associated Infection Surveillance Network (TRANSNET). Clin Infect Dis 50: 1101-1111.

Pappas, P., Kauffman, C., Andes, D., Benjamin Jr, D., Calandra, T., Edwards Jr, J. et al. (2009)

Clinical practice guidelines for the management of candidiasis: 2009 update by the Infectious Diseases Society of America. Clin Infect Dis 48: 503-535.

Pappas, P., Rex, J., Lee, J., Hamill, R., Larsen, R., Powderly, W. et al. (2003) A prospective observational study of candidemia: epidemiology, therapy, and influences on mortality in hospitalized adult and pediatric patients. Clin Infect Dis 37: 634-643.

Park, B., Pappas, P., Wannemuehler, K., Alexander, B., Anaissie, E., Andes, D. et al. (2011) Invasive nonAspergillus mold infections in transplant recipients, United States, 2001-2006. Emerg Infect Dis 17: 1855-1864.

Park, S., Choi, S., Lee, D., Choi, J., Kim, S., Kwon, J. et al. (2011) Serum galactomannan strongly correlates with outcome of invasive aspergillosis in acute leukaemia patients. Mycoses 54: 523-530.

Pasqualotto, A. and Colombo, A. (2010)

Treatment of invasive aspergillosis: a systematic review of randomized clinical trials. Invasive Fungal Inf 4: $18-25$.

Petrikkos, G., Skiada, A., Lortholary, O., Roilides, E., Walsh, T. and Kontoyiannis, D. (2012) Epidemiology and clinical manifestations of mucormycosis. Clin Infect Dis 54(Suppl. 1): S23-S34.

Pfaller, M. and Diekema, D. (2007) Epidemiology of invasive candidiasis: a persistent public health problem. Clin Microbiol Rev 20: 133-163.

Pfeiffer, C., Fine, J. and Safdar, N. (2006) Diagnosis of invasive aspergillosis using a galactomannan assay: a meta-analysis. Clin Infect Dis 42: 1417-1427.

Reboli, A., Rotstein, C., Pappas, P., Chapman, S., Kett, D., Kumar, D. et al. (2007) Anidulafungin versus fluconazole for invasive candidiasis. $N \mathrm{Engl} \mathcal{F} \mathrm{Med}$ 356: 2472-2482.

Revankar, S. and Sutton, D. (2010) Melanized fungi in human disease. Clin Micro Rev 23: 884-928.

Rinaldi, M. (1991) Problems in the diagnosis of invasive fungal diseases. Rev Infect Dis 13: 493-495. 
Rodriguez-Tudela, J., Berenguer, J., Guarro, J., Kantarcioglu, A., Horre, R., de Hoog, G. et al. (2009) Epidemiology and outcome of Scedosporium prolificans infection, a review of 162 cases. Med Mycol 47: 359-370.

Ruhnke, M., Bohme, A., Buchheidt, D., Cornely, O., Donhuijsen, K., Einsele, H. et al. (2012) Diagnosis of invasive fungal infections in hematology and oncology - guidelines from the Infectious Diseases Working Party in Haematology and Oncology of the German Society for Haematology and Oncology (AGIHO). Ann Oncol 23: 823-833.

Sable, C., Strohmaier, K. and Chodakewitz, J. (2008) Advances in antifungal therapy. Ann Rev Med 59: $361-379$.

Safdar, N., Smith, J., Knasinski, V., Sherkow, C., Herrforth, C., Knechtle, S. et al. (2010) Infections after the use of alemtuzumab in solid organ transplant recipients: a comparative study. Diagn Microbiol Infect Dis 66: 7-15.

Segal, B., Herbrecht, R., Stevens, D., OstroskyZeichner, L., Sobel, J., Viscoli, C. et al. (2008) Defining responses to therapy and study outcomes in clinical trials of invasive fungal diseases: Mycoses Study Group and European Organization for Research and Treatment of Cancer consensus criteria. Clin Infect Dis 47: 674-683.

Silveira, F. and Husain, S. (2007) Fungal infections in solid organ transplantation. Med Mycol 45: 305-320.

Singh, N., Avery, R., Munoz, P., Pruett, T., Alexander, B., Jacobs, R. et al. (2003) Trends in risk profiles for and mortality associated with invasive aspergillosis among liver transplant recipients. Clin Infect Dis 36: 46-52.

Singh, N. and Husain, S. (2003) Aspergillus infections after lung transplantation: clinical differences in type of transplant and implications for management. 7 Heart Lung Transplant 22: 258-266.

Singh NM, Husain S; AST Infectious Diseases Community of Practice (2013) Aspergillosis in solid organ transplantation. Am $\mathcal{F}$ Transplant 13(Suppl 4): $228-241$.

Singh, N., Pruett, T., Houston, S., Muñoz, P., Cacciarelli, T., Wagener, M. et al. (2006) Invasive aspergillosis in the recipients of liver retransplantation. Liver Transpl 12: 1205-1209.

Sobel, J. and Revankar, S. (2007) Echinocandins first-choice or first-line therapy for invasive candidiasis? N Engl f Med 356: 2525-2526.

Spellberg, B., Kontoyiannis, D., Fredricks, D., Morris, M., Perfect, J., Chin-Hong, P. et al. (2012) Risk factors for mortality in patients with mucormycosis. Med Mycol 50: 611-618.

Sucher, A., Chahine, E. and Balcer, H. (2009) Echinocandins: the newest class of antifungals. Ann Pharmacother 43: 1647-1657.
Sulahian, A., Boutboul, F., Ribaud, P., Leblanc, T., Lacroix, C. and Derouin, F. (2001) Value of antigen detection using an enzyme immunoassay in the diagnosis and prediction of invasive aspergillosis in two adult and pediatric hematology units during a 4-year prospective study. Cancer 91: 311-318.

Tomblyn M, Chiller T, Einsele H, Gress R, Sepkowitz $\mathrm{K}$, Storek J, et al.; Center for International Blood and Marrow Research; National Marrow Donor program; European Blood and Marrow Transplant Group; American Society of Blood and Marrow Transplantation; Canadian Blood and Marrow Transplant Group; Infectious Diseases Society of America; Society for Healthcare Epidemiology of America; Association of Medical Microbiology and Infectious Disease Canada; Centers for Disease Control and Prevention (2009) Guidelines for preventing infectious complications among hematopoietic cell transplantation recipients: a global perspective. Biol Blood Marrow Transplant 15: 1143-1238.

Trifilio, S., Bennett, C., Yarnold, P., McKoy, J., Parada, J., Mehta, J. et al. (2007) Breakthrough zygomycosis after voriconazole administration among patients with hematologic malignancies who receive hematopoietic stem-cell transplants or intensive chemotherapy. Bone Marrow Transplant 39: 425-429.

Troke, P., Aguirrebengoa, K., Arteaga, C., Ellis, D., Heath, C., Lutsar, I. et al. (2008) Global Scedosporium Study Group. Treatment of scedosporiosis with voriconazole: clinical experience with 107 patients. Antimicrob Agents Chemother 52: $1743-1750$

Ullmann, A. and Cornely, O. (2006) Antifungal prophylaxis for invasive mycoses in high risk patients. Curr Opin Infect Dis 19: 571-576.

van Burik, J., Ratanatharathorn, V., Stepan, D., Miller, C., Lipton, J., Vesole, D. et al. (2004) Micafungin versus fluconazole for prophylaxis against invasive fungal infections during neutropenia in patients undergoing hematopoietic stem cell transplantation. Clin Infect Dis 39: 1407-1416.

Vazquez, J. and Sobel, J. (2006) Anidulafingin: a novel echinocandin. Clin Infect Dis 43: 215-222.

Vazquez, J. and Sobel, J. (2011) Candidiasis, In: Kaufman, C., Pappas, P., Sobel, J. and Dismukes, W. (eds). Essentials of Clinical Mycology, 2nd edition edn, Oxford University Press: Oxford, pp. 167-206.

Viscoli, C., Girmenia, C. and Marinus, A. (1999) Candidemia in cancer patients: a prospective, multicenter surveillance study by the invasive fungal infection group (IFIG) of the European Organization for Research and Treatment of Cancer (EORTC). Clin Infect Dis 28: 1071-1079.

von Eiff, M., Roos, N., Schulten, R., Hesse, M., Zuhlsdorf, M. and van de Loo, J. (1995) Pulmonary aspergillosis: early diagnosis improves survival. Resp Internat Rev Thor Dis 62: 341-347. 
Walsh, T., Anaissie, E., Denning, D., Herbrecht, R., Kontoyiannis, D., Marr, K. et al. (2008) Treatment of aspergillosis: clinical practice guidelines of the Infectious Diseases Society of America. Clinical infectious diseases. Clin Infect Dis 46: 327-360.

Woods, G., Miceli, M., Grazziutti, M., Zhao, W., Barlogie, B. and Anaissie, E. (2007) Serum Aspergillus galactomannan antigen values strongly correlate with outcome of invasive aspergillosis: a study of 56 patients with hematologic cancer. Cancer 110: 830-834.

Xhaard, A., Lanternier, F., Porcher, R., Dannaoui, E., Bergeron, A., Clement, L. et al. (2012) Mucormycosis after allogeneic haematopoietic stem cell transplantation: a French Multicentre Cohort Study (2003-2008). Clin Microbiol Infect 18: E396-E400.

Yang, Y. (2003) Virulence factors of Candida species. f Microbiol Immunol Infect 36: 223-228.

Zou, M., Tang, L., Zhao, S., Zhao, Z., Chen, L., Chen, P. et al. (2012) Systematic review and meta-analysis of detecting galactomannan in bronchoalveolar lavage fluid for diagnosing invasive aspergillosis. PLoS One 7: e433-e447.
Visit SAGE journals online http://tai.sagepub.com

@SAGEJOURNALS 
